frequent relapsers (two relapses in six months or four in one year) is not easy. Cyclophosphamide has proved very efficacious, ${ }^{3}$ in contrast to azathioprine, which has proved a disappointment. ${ }^{4}$ Unfortunately cyclophosphamide has many toxic effects, including haemorrhagic cystitis, marrow depression, reversible alopecia, chromosomal disturbances, and potential sterility. The care required to minimise these risks means that treatment is best given under expert supervision, and then only when further steroid treatment is inadvisable because of unacceptable osteoporosis, stunting of growth, obesity, or striae-effects which can be minimised by not giving prolonged continuous steroid treatment and by precautions on controlling diet. Most children do well even with two or three courses of steroid each year for a year or two; at some time a prolonged six months' course of alternateday treatment (20-30 mg prednisolone every second morning) may be needed. This seems to be a better regimen than three days on and four days off treatment and is certainly less toxic and more likely to permit growth than continuous treatment.

Even when steroid toxicity makes cyclophosphamide treatment necessary it should not begin until a diuresis has been produced by steroids. A high urine volume day and night must be continued throughout treatment and low dosage steroid (10-15 mg prednisolone a day) needs to be given to protect the bone marrow. Parents will accept reversible alopecia. Wigs help and so do photographs of previously bald patients with healthy hair again. When cyclophosphamide has been given (6-8 weeks at $2 \cdot 5-3 \mathrm{mg} \mathrm{kg}$ day) to steroid-responsive but steroid-toxic patients (almost universally with minimal change lesions) some $60^{\circ}{ }_{0}$ remain free of relapse after five years. ${ }^{3}$ This long period free of proteinuria enables the dwarfed, cushiongoid, osteoporotic patient to enjoy a long overdue growth spurt to catch up height and return to a normal, lean shape.

Non-responders to an initial 40-day course of steroid treatment should be assessed by percutaneous renal biopsy, if this has not already been done. Setting aside complex cases, most will show minimal changes with or without focal segmental glomerulosclerosis (FSGS). Those with no FSGS respond completely and spontaneously within a year. Those with FSGS usually do badly. ${ }^{6}$ A reasonable policy after failure of continuous high dosage steroid treatment to clear gross proteinuria is to delay retreatment for three months, maintaining freedom from oedema with diuretics such as frusemide (20-80 mg daily) and spironolactone $100 \mathrm{mg}$ daily. Infections of the urinary tract and elsewhere may be related to non-response, and peritonitis is an especial hazard. Early vigorous broad-spectrum antimicrobial cover (against Gramnegative organisms and streptococci) should be given at the first suspicion of infection. Delay is dangerous. Gramnegative septicaemia, shock, and death occur with frightening speed in children previously treated with steroids. Cyclophosphamide will accelerate the loss of proteinuria in children with minimal change lesions non-responsive to steroids, but its toxicity precludes its use in those circumstances.

Focal segmental glomerulosclerosis is commoner in older ( $>7$ years) girls and carries a poor prognosis. Steroid treatment may ameliorate proteinuria but rarely clears it, and symptomatic diuretic, dietetic, and antimicrobial treatment will be needed. Death may occur within a few years, as the initially scanty lesion spreads to affect a majority of glomeruli and destroy them. ${ }^{6}$ There is no evidence that cyclophosphamide (or any other drug) helps, and such children eventually require long-term haemodialysis or renal transplantation.

\footnotetext{
${ }^{1}$ Seppala, M, et al, Lancet, 1976, 2, 123.
}

2 Arneil, G C, Lancet, 1956, 1, 409.

${ }^{3}$ McDonald, J, Murphy, A V, and Arneil, G C, Lancet, 1974, 2, 980.

- Abramowicz, M, et al, Lancet, 1970, 1, 959.

${ }^{5}$ Barratt, T M, et al, Archives of Disease in Childhood, 1977, 52, 462.

${ }^{6}$ Churg, I, Habib, R, and White, R H R, Lancet, 1970, 1, 1299.

\section{Divers' ear}

Incapacitating ear pain caused by infection of the external canal is one of many important risks for North Sea divers. Traditionally acute otitis externa is associated with swimming - a view supported by Hoadley and $\mathrm{Knight}^{1}$ in their study of 244 people: $7 \cdot 3 \%$ of swimmers had ear complaints but only $3.1 \%$ of non-swimmers. Among 50 divers, however, Sperati and Pefumo $^{2}$ found that nearly half had ear problems compared with only three in a control group. Wright and Alexander ${ }^{3}$ showed that prolonged exposure to water changed the healthy ear flora from Gram-positive cocci and diphtheroids to Gram-negative bacilli and that this change often preceded acute symptoms. Alcock ${ }^{4}$ has now described how in 1974-5 two saturation dives in the North Sea had to be stopped and several others were disrupted by Pseudomonas aeruginosa ear infection affecting the diving team. Saturation dives, in which the divers stay at high atmospheric pressures, are planned to last anything from seven to 30 days or more. Severe ear pain caused by infection may make the demanding work impossible. With decompression and treatment the acute symptoms rapidly subside, but decompression is costly in both time and money and interferes with essential diving schedules.

In a typical saturation dive some six to eight men live inside a complex of several linked steel pressure chambers on the deck of a ship or oil rig. There is usually a main living chamber and a wash basin, shower, and lavatory as well as sleeping space. Divers move to and from the sea bed in a diving bell which can be keyed on to the pressure chamber through an air lock. The atmosphere is a pressurised mixture of helium and oxygen. The ambient temperature varies from 30 to $35^{\circ} \mathrm{C}$ and the relative humidity is $55 \%$ or more. Men descend in the bell to the sea bed, often for four to eight hours each day, typically for nine of 14 days in saturation. Decompression lasts for 50 hours or more. The complexity of the system, the arduous hours of work, and the waiting in cramped and humid conditions all increase the likelihood that opportunist pathogens will flourish.

To minimise the incidence of ear infection Alcock screened all divers before entering saturation, and those carrying Gramnegative organisms in their ears were excluded. Of 58 divers so screened, only one $(2 \%)$ carried $P$ aeruginosa. Seven days after entering the diving complex up to $70 \%$ harboured different species of Gram-negative organisms; $P$ aeruginosa was isolated at some stage from $82 \%$ of them. Some 10 of the 58 divers who were in saturation for up to 30 days developed pain in the ear and in eight of these $10 P$ aeruginosa was isolated. Ear swabs were collected by the divers themselves at two-day intervals during saturation, and as soon as these showed Gram-negative bacilli the men were treated with ear drops containing gentamicin and polymyxin $\mathrm{B}$; in the event, only two of the treated divers suffered pain. In addition to these measures an attempt was made to reduce contamination by Gram-negative organisms in the saturation chambers. This was found to be greatest in the washing and lavatory areas and the men's bedding. Intensive scrubbing of the chamber with detergent solution and the use of dichlorophen disinfectant 
during dives, together with a daily supply of clean bedding, reduced the extent of contamination. Only a very restricted range of chemical disinfectants can be used in a pressurised chamber, so not surprisingly contamination could not be completely controlled.

$P$ aeruginosa is a commensal in the bowel and on the skin of a variable number of healthy people and it would be impossible to eliminate all sources of infection among divers. By serotyping the pseudomonads isolated in one dive Alcock found that type II strains accounted for 16 of 18 isolates from the men's ears and 11 out of 12 isolates from the chamber. A single diver with type II in his ears had entered this dive; phage typing showed that all the strains isolated were indistinguishable. In other dives, too, the strains of $P$ aeruginosa isolated belonged to a few serotypes, suggesting that a single diver may often be the source of organisms which spread throughout the chamber complex.

Screening may reduce the chances of divers suffering from acute infection early in the dive, but it has not been effective in reducing the number who eventually harbour Pseudomonas in their ears. The usually recommended prophylactics have given disappointing results. Skin sensitisation and the risk of spreading resistant bacteria are among the dangers associated with topical antibiotics, and drugs such as gentamicin should not be used without clear indications. In practical terms, however, Alcock's study was a success: he had no problems with sensitisation, and resistant strains of $P$ aeruginosa were rarely and briefly found only during an early trial with antibiotic cream. Treated divers rarely suffered from pain in the ears, dives were no longer disrupted, and the operational demands of a highly organised and essential industry were met. ${ }^{1}$ Hoadley, A W, and Knight, D E, Archives of Environmental Health, 1975,
30, 445.

2 Sperati, G, and Pefumo, G, Archivio Italiano di Otologia, Rinologia e Laringologia, 1967, 78, 443.

3 Wright, D N, and Alexander, J M, Archives of Otolaryngology, 1974, 99, 15.

${ }^{4}$ Alcock, S R, Fournal of Hygiene, Cambridge, 1977, 78, 395.

\section{Treatment of depression}

The treatment of depression continues to be a matter of debate, including as it does such diverse remedies as lithium, L-tryptophan, tricyclic antidepressants, monoamine-oxidase inhibitors, and electric convulsion therapy (ECT). A meeting held recently in Glasgow ${ }^{1}$ discussed all these forms of treatment-not only their practical aspects but also the possible biochemical basis of their modes of action.

The results of a recent trial ${ }^{2}$ in Glasgow of antidepressant drugs, given by $\mathrm{R} \mathrm{N}$ Herrington, led to some discussion about the optimum dose of L-tryptophan. This difficulty had arisen because the drug induces the activity of the main degradative enzyme of tryptophan in the liver, tryptophan pyrrolase. ${ }^{3}$ Doses of tryptophan over $4 \mathrm{~g}$ per day might be self-defeating in so far as they resulted in a more rapid degradation of the amino-acid in the liver. Herrington also reported the results of the trial of ECT against L-tryptophan in severe depression, ${ }^{4}$ which had shown the superiority of the former. This report was followed by three other papers dealing with the use of ECT, an emphasis which was appropriate in view of the current controversy surrounding this treatment and the recent memorandum $^{5}$ issued by the Royal College of Psychiatrists. J A G Watt discussed both current medicolegal problems in using ECT and the indications for its use, which included resistance to drug treatment, untoward drug side effects, and severe depression. In view of the wide interest in its efficacy C Freeman's report of a double-blind trial of ECT was especially timely. His control group had had two "dummy ECT" sessions the first week followed by ECT as long as necessary, while the trial group simply received ECT. The results showed that there was no mood improvement after dummy ECT, whereas there was definite marked improvement after the first two genuine shocks. The final outcome was similar in the two groups except that controls took about one week longer (the time that dummy ECT was given) for the improvement to occur.

A R Green described recent studies of the daily administration of rats and mice of an electroconvulsive shock over several days. This produced enhanced behavioural responses to brain 5-hydroxytryptamine (5-HT) and catecholamine receptor stimulation. ${ }^{6-8}$ The failure of subconvulsive shocks to evoke the enhancement and the ability of the convulsant inhalant Indoklon (a drug that has been used ${ }^{9}$ in place of ECT) to produce similar changes suggested that ECT may produce its therapeutic action by a change in monoamine receptor responses.

Dealing with the biochemical aspects of depression, the meeting gave most attention to the part played by $5-\mathrm{HT}$, for which there is now reasonable evidence. Nevertheless, catecholamines also have an important role in depression, ${ }^{10}$ and $\mathrm{D}$ Eccleston discussed the probable interactions of catecholamines and 5-HT, suggesting that in fact the indoleamine $^{11}$ and catecholamine ${ }^{10}$ theories of depression may well be compatible.

While the symposium did not establish clear indications for specific antidepressant treatments, it did give some insight into their relative merits and associated difficulties. It also enabled psychiatrists to hear of some of the experimental approaches now being used to investigate the aetiology of depression.

1 Organised by the West of Scotland Postgraduate Education Committee, the Scottish Medical fournal, and Merck Pharmaceuticals.

${ }^{2}$ Herrington, R N, et al, Lancet, 1974, 2, 731.

${ }^{3} \mathrm{Knox}, \mathrm{W}$ E, and Auerbach, V H, Journal of Biological Chemistry, 1955, 214, 307.

${ }^{4}$ Herrington, R N, et al, Psychological Medicine, 1976, 6, 673.

${ }^{5}$ Royal College of Psychiatrists, British fournal of Psychiatry, 1977, 131, 261

${ }^{6}$ Evans, J P M, et al, British fournal of Pharmacology, 1967, 56, 193.

7 Green, A R, Heal, D J, and Grahame-Smith, D G, Psychopharmacology, 1977, 52, 195.

${ }^{8}$ Modigh, K, Fournal of Neural Transmission, 1975, 36, 19.

${ }^{9}$ Small, I F, in Psychobiology of Convulsive Therapy, ed M Fink et al, p 65. Washington, DC, Winston, 1974.

${ }^{10}$ Schildkraut, J J, et al, American fournal of Psychiatry, 1967, 124, 600.

11 Van Praag, H, in Neuroregulators and Psychiatric Disorders, ed E Usdin et al, p 163. New York, Oxford University Press, 1977.

\section{Dietary calcium}

For over a quarter of a century we have known that the intestinal absorption of calcium can be adapted to changes in dietary intake. ${ }^{1}$ Severe restriction of dietary calcium in man evokes homoeostatic responses from intestine, kidney, and bone. ${ }^{2}$ In experiments on animals calcium deprivation has been shown to lead to osteoporosis as skeletal reserves are mobilised to maintain normocalcaemia. ${ }^{3}$ Clearly, then, estimates of the minimum dietary requirement for calcium 